ARTIGO

\title{
AUTORIA DOCENTE: UM ESQUEMA DE ANÁLISE NO ENSINO DE CIÊNCIAS
}

\author{
JULIANA DE OLIVEIRA MAIA ${ }^{1}$ \\ ORCID: https://orcid.org/0000-0002-7388-4420 \\ ALBERTO VILLANI ${ }^{2}$ \\ ORCID: https://orcid.org/0000-0003-2760-240X \\ ELISABETH BAROLLI ${ }^{3}$ \\ ORCID: https://orcid.org/0000-0001-9736-107X \\ WILSON ELMER NASCIMENTO ${ }^{4}$ \\ ORCID: https://orcid.org/0000-0002-9802-3192
}

\begin{abstract}
RESUMO: Este trabalho tem como objetivo apresentar um esquema de análise para a autoria docente no ensino de Ciências. O conceito de autoria docente foi caracterizado de modo a aprofundar a relação que o professor, em contextos de formação continuada, estabelece com seu próprio desenvolvimento profissional docente. A elaboração do esquema teve como ponto de partida depoimentos de professores participantes de cursos de Mestrados Profissionais em Ensino de Ciências e Matemática extraídos de trabalhos publicados em periódicos brasileiros. O esquema abrange um conjunto de indicadores que dão conta tanto de fatores de natureza cognitiva, quanto subjetiva que influenciam o desenvolvimento profissional docente: dedicação - nula, passiva e ativa; responsabilidade - nula, eventual e sistemática; inovação - nula, técnica, reflexiva e criativa. De modo a explorar o esquema analítico, foram interpretados dados empíricos sobre a participação de uma professora em um Mestrado Profissional em Ensino de Física. O conjunto de dados foi obtido por meio de uma entrevista semiestruturada e para o processo de apresentação e análise dos dados optou-se por uma análise narrativa. Como conclusão foi possível observar que o esquema desenvolvido para caracterizar a autoria docente tem como perspectiva dar destaque ao fato de que o professor pode ser original e criativo também quando se considera, em específico, os conhecimentos que podem estar relacionados com as diversas atividades da prática pedagógica. Além disso, o esquema pode se constituir num instrumento efetivo, seja para o professor se auto avaliar, seja para fornecer indícios acerca do potencial de contribuição das atividades propostas pelo contexto formativo.
\end{abstract}

\footnotetext{
${ }^{1}$ Doutora em Ensino de Ciências (modalidade Ensino de Química) pela Universidade de São Paulo (USP) e editora de materiais didáticos da Editora Moderna. São Paulo, SP, Brasil.<14julianamaia@gmail.com>

${ }^{2}$ Doutor em Física pela Universidade Estadual Paulista Júlio de Mesquita Filho (UNESP) e professor sênior do Instituto de Física da Universidade de São Paulo (USP). São Paulo, SP, Brasil. < avillani@if.usp.br>

${ }^{3}$ Doutora em Educação pela Universidade de São Paulo (USP) e professora da Faculdade de Educação da Universidade Estadual de Campinas (UNICAMP). Campinas, SP, Brasil. <ebarolli@unicamp.br>

${ }^{4}$ Doutor em Ensino de Ciências e Matemática pela Universidade Estadual de Campinas (UNICAMP) e professor do Centro de Educação da Universidade Federal do Rio Grande do Norte (UFRN). Natal, RN, Brasil. <wilson-elmer@hotmail.com> Educação em Revista|Belo Horizonte|v.36|e236529|2020
} 
Palavras-chave: Autoria docente, desenvolvimento profissional docente, Professores de Ciências, Formação de professores

\title{
TEACHING AUTHORSHIP: AN ANALYSIS SCHEME IN THE TEACHING OF SCIENCE
}

\begin{abstract}
This work presents an analysis scheme for teaching authorship in science teaching. The concept of teaching authorship has been characterized in order to deepen the relationship that the teacher, in contexts of continuous formation, establishes with his own professional teacher development. The elaboration of the scheme had as a starting point testimonials of teachers, participants of courses of Professional Masters in Teaching of Sciences and Mathematics, extracted from works published in Brazilian periodicals. The scheme encompasses a set of indicators that account for both cognitive and subjective factors that influence teacher professional development: dedication - null, passive and active; responsibility - null, eventual and systematic; innovation - null, technical, reflective and creative. To explore the scheme of analysis, we have interpreted empirical data on the participation of a teacher in a Professional Master's Degree in Physics Teaching. The data set was obtained by means of a semistructured interview and for the process of presentation and analysis of the data we opted for a narrative analysis. As a conclusion, it was possible to observe that the scheme developed to characterize the teaching author has as a perspective to highlight the fact that the teacher can be original and creative also when considering, in specific, the knowledge that can be related to the diverse activities of the practice pedagogical. In addition, the scheme can be an effective instrument, either for the teacher to evaluate himself or to provide evidence about the potential contribution of the activities proposed by the training context.
\end{abstract}

Keywords: Teaching authorship, Professional teacher development, Science Teachers, Teacher training

\section{AUTORÍA DOCENTE: UM ESQUEMA DE ANÁLISIS EN LA ENSEÑANZA DE CIENCIAS}

RESÚMEN: Este trabajo tiene como objetivo presentar un esquema de análisis para la enseñanza de la autoría en la enseñanza de las ciencias. El concepto de autoría docente se caracterizó para profundizar la relación que el profesor, en contextos de educación continua, establece con su propio desarrollo profesional docente. La preparación del esquema contó con testimonios de profesores, participantes en cursos de Maestría Profesional en Enseñanza de Ciencias y Matemáticas, como punto de partida, extraídos de trabajos publicados en revistas brasileñas. El esquema cubre un conjunto de indicadores que explican los factores cognitivos y subjetivos que influyen en el desarrollo profesional del maestro: dedicación: nula, pasiva y activa; responsabilidad: nula, eventual y sistemática; innovación: nula, técnica, reflexiva y creativa. Para explorar el esquema analítico, se interpretaron datos empíricos sobre la participación de un profesor en un Máster Profesional en Enseñanza de Física. El conjunto de datos se obtuvo a través de una entrevista semiestructurada y para el proceso de presentación y análisis de datos, se eligió un análisis narrativo. Como conclusión, fue posible observar que el esquema desarrollado para caracterizar la autoría docente tiene la perspectiva de resaltar el hecho de que el maestro también puede ser original y creativo al considerar, en particular, el conocimiento que puede estar relacionado con las diversas actividades de la práctica pedagógica. Además, el esquema puede ser un instrumento efectivo, ya sea para que el maestro se evalúe a sí mismo o para proporcionar evidencia sobre la contribución potencial de las actividades propuestas por el contexto de capacitación.

Palabras clave: Autoría docente, Desarrollo profesional docente, Profesores de ciencias, Formación de profesores 


\section{INTRODUÇÃO}

A maneira com que atuais gestores brasileiros vêm legislando ou mesmo conduzindo muitas das políticas públicas na área da educação, como foi o caso das alterações efetuadas em 2016 (Medida Provisória 746/2016) na Lei de Diretrizes e Bases da Educação (Lei n 9394/96), mostra-se alheia ao que os resultados das pesquisas educacionais têm apontado há décadas. De fato, as pesquisas que passaram a ser desenvolvidas a partir da década de 1990, sobretudo com os trabalhos de Maurice Tardif, Lee Shulman, Clermont Gauthier, Philippe Perrenoud, António Nóvoa, Marilyn Cochran-Smith, Susan Lytle etc., ilustram o esforço da área de formação de professores em inventariar saberes, conhecimentos, competências e habilidades característicos de uma profissão complexa. Guimarães (1996), inclusive, sistematizou os saberes referentes à prática docente, destacando modelos que tiveram por objetivo agrupar autores, correntes e opiniões sobre o conhecimento/pensamento do professor, tais como o modelo cognitivo, o de Elbaz e o de Barth. Todos esses modelos compartilham de dois pressupostos comuns: o primeiro é que o conhecimento é pessoal e dinâmico, estando em constante desenvolvimento; o segundo é que o conhecimento é de natureza situada, contextual.

Todo esse conhecimento alcançado pelas pesquisas contribuiu não só para revelar a complexidade da profissão, mas também para subsidiar o planejamento de contextos propícios ao desenvolvimento profissional docente (PONTE, 1998; PERRENOUD, 2000; DAY, 2001; VILLEGASREIMERS, 2003; MARCELO, 2009; NÓVOA, 2009). Nessa perspectiva foram organizados, entre outros, cursos de especialização e de Mestrados Profissionais que buscam oferecer aos professores em exercício condições para aprofundar seus saberes pedagógicos e sua competência na prática do magistério.

Entretanto, mais recentemente, alguns pesquisadores vêm dando destaque ao fato de que há diferenças entre as maneiras pelas quais os conhecimentos são mobilizados pelos professores em suas práticas. Mais especificamente, um conhecimento, como por exemplo, o pedagógico do conteúdo, pode fazer parte do repertório pedagógico de vários professores, mas, dificilmente, a maneira pela qual nele se apoiam em suas práticas será exatamente a mesma. Isso nos remete ao fato, quase óbvio, de que a aprendizagem dos conhecimentos próprios do magistério não se dá de forma homogênea.

Assim, do ponto de vista das pesquisas que se dedicam a pensar a profissão num nível em que se busca interpretar, compreender e atribuir significado às particularidades e singularidades pelas quais os professores se desenvolvem profissionalmente e conduzem seu ensino, novas referências teóricas e metodológicas se fazem necessárias.

Nessa direção, o conceito de autoria tem comparecido em diversos trabalhos, fazendo referências à qualidade da produção docente, de modo a expressar, justamente, as particularidades na maneira pelas quais os professores mobilizam os conhecimentos próprios da profissão.

No trabalho de Gois e Santos (2014), por exemplo, o termo autoria comparece associado à habilidade do professor produzir algo relacionado ao seu fazer pedagógico ou a seu desenvolvimento profissional. Nesse caso, a autoria se revela na elaboração de um objeto educacional (um problema, uma simulação, um texto) ou como forma de protagonismo no planejamento e desenvolvimento da aula. Nascimento e Rezende Júnior (2010) relacionam o termo autoria à autonomia do futuro professor no desenvolvimento de habilidades que lhe permitem propor questões relevantes para os alunos.

Alguns trabalhos associam a autoria com a qualidade da produção textual de futuros professores, apoiados no esquema proposto por Eni Orlandi que define três categorias de repetição: empírica (produção "recorte" e "cola"), formal (elaboração de paráfrases) e histórica (produção original) (DIAS; ALMEIDA, 2010; ALMEIDA, 2012; MASSI; QUEIROZ, 2012).

Em termos das contribuições para a área de formação de professores, há que se considerar que os trabalhos citados têm por tendência associar o termo autoria à produção pelo professor ou futuro professor, de algo, procurando explicitar aspectos que poderiam caracterizar a maneira pela qual a produção foi por ele realizada. A própria Orlandi (2004), ao situar a produção discursiva dos sujeitos em três patamares diferentes: empírico, formal e histórico, tem por objetivo destacar as diferenças na maneira pela qual uma atividade pode ser realizada. Ou seja, a produção de algo pode ser feita de diferentes formas, que podem ser caracterizadas por diferentes graus de intensidade e de originalidade também. Não podemos deixar de reconhecer que um plano de aula, mesmo que não seja original, pode ser 
elaborado com muito ou pouco investimento e cuidado, no que se refere às características do processo de ensino. Além disso, assim como qualquer profissional, a relação que o professor estabelece com sua atividade depende de vários fatores, inclusive daqueles próprios do campo da subjetividade. Estamos partindo do pressuposto de que as ações humanas são permeadas pela subjetividade, isto é, pelas metas e interesses a que os sujeitos se propõem e pela singularidade com que se relacionam com a profissão, veem o mundo e conferem significado a ele.

Contreras (2002), por sua vez, cunhou o termo autonomia para referir-se à relação do professor com a própria profissão, destacando numa perspectiva global três tipos ou modelos de profissionais: o especialista técnico, o reflexivo e o intelectual crítico. Desse modo, ele também diferencia as maneiras pelas quais os professores desempenham sua atividade profissional, embora sem considerar as especificidades dos diferentes conhecimentos que compõem a prática do magistério. Para ele, autonomia e emancipação tornam-se sinônimos, uma vez que supõe um processo de descobertas e de transformações da prática diária, bem como de aspirações sociais e educativas norteadas pelos valores da igualdade, justiça e democracia.

A proposição desses três modelos de professores tem sido justificada com uma "fundamentação de base, tanto epistemológica como puramente pedagógica" (CONTRERAS, 2002, p. 90). Considera o autor que, para cada modelo, está associado um tipo de racionalidade pedagógica: técnica, prática e crítica. São essas racionalidades que indicariam o grau de autonomia do professor: desde uma autonomia ilusória, passando por uma autonomia moral e individual, atingindo uma autonomia como emancipação.

De acordo com este autor, os especialistas técnicos são aqueles que apenas aplicam os conhecimentos produzidos por outros, enquanto para o profissional reflexivo, a prática constitui-se em um processo que se abre para solucionar os problemas de acordo com determinados fins, compreendendo a situação e tentando modificá-la. Finalmente, o intelectual crítico teria a capacidade não só de promover, desenvolver e solucionar os problemas decorrentes do ensino a partir de uma ação com sentido moral, mas sobretudo no sentido político e social, comprometido com a transformação do pensamento. A nosso ver, esses diferentes tipos de racionalidade pedagógica têm compatibilidade com o termo autoria. É possível afirmar que, para cada um dos modelos, a produção do professor guarda características distintas em relação à maneira com que avança em seu processo de transformação pessoal, organizacional e social. Em particular, Contreras (2002) questiona sobre o que deveria ser um ensino valioso sem se limitar apenas às perguntas sobre o como, mas busca repensar e reinventar continuamente sua prática.

De modo análogo a Contreras, também estamos interessados em caracterizar o compromisso que um professor assume com as diversas dimensões de seu desenvolvimento profissional, compromisso este que estamos denominando autoria. Como, então, poderíamos elaborar um conceito de autoria que desse conta das particularidades de um processo de formação de professores ou de desenvolvimento profissional docente sempre atravessado por diferentes fatores?

Nossa hipótese é que o conceito de autoria pode ser apreendido empiricamente e depois teorizado a partir da interação do professor com situações que se referem a determinados processos formativos. Se nossa hipótese é plausível, podemos eleger o Mestrado Profissional (MP) como uma dessas situações, pois trata-se de um curso de pós-graduação que exige o cumprimento de um conjunto de atividades: disciplinas de natureza científicas e pedagógicas; participação em seminários, em eventos da área e em fóruns de discussão; elaboração de uma dissertação e de um produto educacional e defesa desses trabalhos de conclusão de curso. A nosso ver, se constitui como espaço privilegiado no qual os professores têm a oportunidade de realizar produções de naturezas diversificadas. Além disso, as experiências dos professores podem ser valorizadas no sentido de mergulharem em suas inquietações cotidianas e as tornarem objeto de investigação para avançar na sua prática educativa e na sua concepção sobre educação, ou seja, se desenvolverem profissionalmente. Dentre os vários trabalhos divulgados na literatura, nos chama a atenção o fato de que os professores se relacionam de diferentes maneiras com as atividades que realizam nos cursos de MP. Inclusive, mesmo em se tratando de um mesmo curso, pudemos observar que os professores aproveitam das atividades propostas de diferentes formas 
(CEVALLOS, 2011; SANTOS et al, 2012; PIRES; IGLORI, 2013; SCHÄFER; OSTERMANN, 2013a, 2013b; CURI; AMARAL, 2013).

Por exemplo, em muitas situações, podemos encontrar um professor que decidiu cursar o MP e que, nesse processo, articulou as aprendizagens que obteve nas disciplinas com sua prática docente e buscou novas leituras, além das solicitadas pelo curso. Também elaborou um produto educacional não só original, mas que atendia suas próprias demandas; enfim, se apoiou no curso para suprir suas próprias finalidades educativas. Há situações, entretanto, nas quais um professor que entrou no MP certamente teve outro tipo de relação com o curso. Cumpriu as demandas, mas não procurou estabelecer uma relação com sua prática educativa, realizou somente as tarefas e leituras que lhe eram solicitadas, elaborou um produto educacional porque era uma etapa exigida para obtenção do título, mas não um produto que procurava atender diretamente suas necessidades educativas, provavelmente porque ele não as possuía de forma significativa. Neste trabalho, nosso objetivo foi estabelecer um conjunto de indicadores que, ao mesmo tempo em que contribuem para explicitar essas idiossincrasias, dão conta de um esquema de análise que articula fatores de natureza cognitiva e subjetiva que influenciam o desenvolvimento profissional docente. Para tanto, fomos buscar depoimentos de professores no âmbito de contextos formativos, elementos que podem caracterizar a relação dos professores com seu desenvolvimento profissional. A funcionalidade e o potencial desse esquema também são apresentados por meio da interpretação de dados empíricos sobre a participação de uma professora de Física em um curso de Mestrado Profissional em Ensino de Física (MPEF).

\section{CONSIDERAÇÕES TEÓRICO-METODOLÓGICAS}

A realização deste trabalho se pautou, numa primeira etapa, em cotejar os depoimentos dos professores, participantes de cursos de Mestrados Profissionais em Ensino de Ciências e Matemática, extraídos de trabalhos já publicados. Buscamos trabalhos que apresentavam entrevistas de professores nas quais manifestavam a maneira pela qual realizaram diferentes atividades propostas naquele contexto formativo. Os trabalhos de Cevallos (2011), Santos et al, (2012), Pires e Iglori (2013), Curi e Amaral (2013) e Maia (2017) foram selecionados pelo fato de apresentarem depoimentos com a densidade necessária para que pudéssemos inferir elementos que se apresentavam como mais significativos e que caracterizavam a relação do professor com as atividades por ele desenvolvidas em cursos de MP. Desse modo, para cada um dos depoimentos considerados, buscamos explicitar essa relação de modo a dar visibilidade ao compromisso do professor com determinada atividade.

Todos esses depoimentos expressam, na visão dos próprios professores, as maneiras pelas quais realizaram as atividades propostas, o que nos permitiu inferir, por um lado, o desenvolvimento profissional pretendido pelo professor ao realizar determinada atividade e, por outro, caracterizar a implicação ou o investimento do professor para alcançar o desenvolvimento favorecido pela atividade.

No processo de desenvolvimento profissional ao longo de um curso como o de MP, é esperado que as diferentes atividades propostas favoreçam também a construção, pelo professor, de diferentes saberes da profissão. Ou seja, o MP, tomado nessa perspectiva, deverá agregar ao conhecimento de base trazido pelo professor, novos conhecimentos relacionados às diferentes dimensões do desenvolvimento profissional.

Em outro trabalho (BAROLLI et al., 2019) propusemos um conjunto de dimensões apoiado em diversos pesquisadores que têm contribuído para pesquisas que se propõem a analisar processos de desenvolvimento profissional de professores (DAY, 2001; MARCELO, 2009; NÓVOA, 2009; PERRENOUD, 2000; PONTE, 1998; VILLEGAS-REIMERS, 2003). Este conjunto de dimensões nos serviu de referencial para analisar os avanços em termos de aprendizagem da docência que os depoimentos dos professores nos sinalizaram. Em síntese, Barolli e colaboradores (2019) partem de uma compreensão de desenvolvimento profissional docente como um processo no qual a produção de novos saberes se efetiva pelo diálogo com interlocutores que vão configurando a atividade docente: a academia, a escola e a sociedade. Fundamentado nesses diálogos, foi elaborado um esquema de análise com o potencial de caracterizar o desenvolvimento profissional de professores de Ciências por meio de oito dimensões. 
O diálogo com a academia representa a possibilidade de o professor atualizar, ampliar e aprofundar saberes de natureza científica e pedagógica. Ou seja, constituem-se dimensões de desenvolvimento profissional, a atualização nos conhecimentos científicos e a atualização nos conhecimentos pedagógicos. Atualizações dessas naturezas podem, ainda, impactar a maneira pela qual os professores conduzem suas práticas pedagógicas, o que nos sugere três outras dimensões para o desenvolvimento profissional: organização e condução do ensino, sustentação da aprendizagem dos alunos e investigação da própria prática, dimensões que envolvem simultaneamente também o diálogo com a escola. Esta também representa um espaço de troca de experiências e de organização das atividades promovidas pelos colegas e coordenadores da escola, que resultam no amadurecimento grupal e na gestão escolar. A partir daí definiu-se outra dimensão: participação na gestão escolar. Este referencial considera ainda que o processo de desenvolvimento profissional também está articulado ao diálogo com a sociedade. Isto é, esse diálogo representa a escuta que o professor faz, bem como seu posicionamento, frente às iniciativas promovidas pelas autoridades educacionais e cíveis, e pelas instituições que promovem a justiça social. Compatível com essa perspectiva foi definida a dimensão participação na responsabilidade social. Transversal a esses diálogos, os autores definem, ainda, uma última dimensão, denominada planejamento da carreira profissional. Cabe ressaltar que cada uma das oito dimensões implica um conjunto de indicadores que estão associados aos diversos saberes docentes apontados pela literatura educacional (BAROLLI et al., 2019).

Embora essas oito dimensões indiquem saberes que, além de caracterizar a profissão docente, são imprescindíveis para o desenvolvimento profissional de professores de Ciências, há que se considerar a importância de avaliar a intensidade com que cada dimensão é alcançada pelo professor. Entendemos, portanto, que cada uma das dimensões admite uma graduação em intensidade que vai de um mínimo de inovação e consciência a um máximo de originalidade e reflexão, caracterizando o desenvolvimento profissional ideal na dimensão analisada. Nesse sentido o desenvolvimento profissional seria mais bem caracterizado a partir de dois eixos: um que revela a amplitude ou abrangência, e outro, a intensidade. Dar conta deste segundo eixo requereu outro esforço no sentido de estabelecer novos indicadores capazes de indicar a profundidade com que um professor se desenvolveu num determinado aspecto pertencente a uma ou mais das dimensões. O estabelecimento desses indicadores compõe o conceito de autoria que pretendemos desenvolver neste trabalho.

Numa segunda etapa, de modo a explorar o potencial do esquema de análise elaborado, buscamos interpretar dados empíricos sobre a participação de uma professora de Física em um curso de Mestrado Profissional em Ensino de Física (MPEF). A escolha da participante da pesquisa foi baseada nos seguintes critérios: i) tempo de docência superior a dez anos; ii) atuação docente em uma instituição pública de educação básica; iii) disponibilidade para relatar em profundidade seu desempenho durante a participação no curso. Esses critérios foram estabelecidos tendo em vista a possibilidade de investigar a trajetória de uma professora considerada experiente, bem como um contexto de atuação profissional que garantisse certo grau de autonomia e liberdade para criar.

O contato com a participante da pesquisa deu-se durante a implementação de um projeto de maior envergadura financiado pelo Conselho Nacional de Desenvolvimento Científico e Tecnológico (CNPq) entre os anos de 2013 e 2017. Alinhados com as recomendações éticas da pesquisa que envolve seres humanos, informamos a professora sobre os objetivos da pesquisa por meio de um Termo de Consentimento Livre e Esclarecido.

A coleta de dados foi realizada em local da preferência da participante, na universidade onde realizava seu doutorado. A entrevista pautou-se na exploração da trajetória da professora durante o processo formativo no MP, destacando as disciplinas que mais lhe chamaram atenção, a escolha do orientador, do tema de pesquisa, sua elaboração, implementação e avaliação, bem como outras produções. A partir de questionamentos dessa natureza o entrevistador conduziu a entrevista acrescentando novas indagações e inferências que porventura surgissem no processo (TRIVIÑOS, 1992), mas levando em consideração um roteiro estabelecido previamente.

Com o consentimento prévio da professora, a entrevista foi registrada por meio de gravação em áudio, de modo que toda a atenção do pesquisador fosse direcionada para a entrevistada. A entrevista foi transcrita em sua totalidade e passaram por uma "conferência de fidedignidade", ou seja, pelo 
procedimento de ouvir a gravação realizando a leitura do texto transcrito, possibilitando, assim, a correção dos erros ao acompanhar e conferir cada trecho (DUARTE, 2004).

Para o processo de apresentação e análise dos dados optamos pela análise narrativa (CLANDININ; CONNELLY, 2011; CURY, 2013), que consiste na produção de uma narrativa a partir do depoimento do entrevistado. $\mathrm{Na}$ análise narrativa, se coletam descrições de eventos marcantes, bem como de outros acontecimentos e, a partir disso, é gerada uma narrativa como produto de pesquisa (PEREIRA, 2006). Essa metodologia desempenha o papel de construir o significado das experiências dos sujeitos mediante a apreensão de "elementos unificadores e idiossincráticos, buscando com isso, um desvelamento do modo autêntico da vida individual dos depoentes e da situação/contexto investigado" (CURY, 2013, p. 158).

A análise narrativa reconstrói a trajetória da professora Francis (nome fictício) no contexto formativo do MPEF em uma perspectiva diacrônica, que articula descrições e interpretações sustentadas pelo esquema de análise que caracteriza a autoria e o desenvolvimento profissional docente.

A seguir, nos próximos dois itens, será explicitado o processo de obtenção dos indicadores que compõem nossa conceituação de autoria, e que se caracteriza como nosso esquema de análise. Com base nesse esquema, elaboramos, no item seguinte, a análise narrativa da trajetória da professora Francis no contexto formativo da MPEF.

\section{O PROCESSO DE FORMAÇÃO DOCENTE E O CONCEITO DE AUTORIA}

Uma primeira pista pode ser percebida no depoimento de uma professora que participou de um curso de MP em Ensino de Matemática, oferecido por uma Universidade Estadual. Nesse depoimento, a professora procura esclarecer ao entrevistador sobre o fato de ter empreendido esforços no sentido de implementar em sua escola atividades aprendidas no curso de MP realizado.

O último módulo era sobre objeto de aprendizagem e no decorrer da disciplina uma das professoras solicitou que a gente tinha que escolher um desses objetos de aprendizagem e falar sobre ele na aula. Quando eu conheci isso eu achei muito interessante. Eu não costumava usar recursos tecnológicos na sala de aula. Então, eu conheci esses objetos, escolhi alguns que se encaixavam com o que eu estava trabalhando na escola e apliquei com os alunos na minha aula. Por eu ter conhecido esse depositório tecnológico na disciplina eu achei que seria mais interessante aplicar na minha aula do que eu simplesmente só aprender a mexer naquilo. (Rúbia reproduzido de MAIA, 2017, p. 99, grifo nosso).

Chama a atenção o fato de que a professora ao participar da atividade se surpreende com os tais objetos de aprendizagem e com a possibilidade de eles fazerem parte das estratégias de condução das suas aulas. Assim, manifesta um investimento em conhecer ou aprender sobre os objetos para incluí-los em seu repertório pedagógico. Nesse sentido, esse conhecimento vai redundar em seu desenvolvimento profissional, isto é, num certo impacto sobre sua satisfação pessoal e sobre a atualização de seu repertório pedagógico e sobre sua prática. Na medida em que, como ela afirma, tomou a iniciativa de levá-lo para a sala de aula e aplicá-lo junto aos seus alunos, podemos afirmar que, sob esse ponto de vista, há uma responsabilização da professora com relação à estratégia didática, pois a partir do momento em que ela entra noutro contexto que não é mais o âmbito do MP, mas sim da sua gestão na sala de aula, é ela quem assume os riscos e responsabilidade pelo novo conhecimento. Finalmente, o depoimento também nos permite afirmar que para essa professora essa estratégia tem um caráter de originalidade, já que representa para sua prática, uma inovação.

No trabalho de Santos et al. (2012) também foi possível perceber através da narrativa do professor nomeado como Egresso A que o curso o impactou na sua forma de pensar a profissão docente e de seu fazer pedagógico.

O mestrado mudou principalmente a [...] opinião formada que a gente já tinha a respeito da didática, a respeito das metodologias de ensino, porque antes da gente começar a estudar a fundo este tipo de pesquisa, a gente sempre acha que é brincadeira, é uma forma que se tem de enrolar, de fazer com que a prática seja transformada em fantasia; que a teoria nunca tem como ser aplicada na prática, e a gente começa a ver que não. A gente percebe que quando você começa a 
estudar essas novas metodologias você vê que sim, que isso é possível ser colocado na prática, que nós professores podemos nos especializar cada vez mais (Egresso $\mathrm{A}$ reproduzido de SANTOS et al. 2012, p. 129, grifo nosso).

Fica evidente, nesse depoimento, o fato de que o professor se surpreende quando se dá conta da possibilidade de articular teoria e prática, de transformar a "fantasia" em realidade, e não o contrário. Em outras palavras, o que parece estar em jogo é o fato de o professor reconhecer que as orientações da Didática, sobretudo no que se refere às inovações metodológicas, podem ser incorporadas em seu repertório pedagógico e, dessa forma, levadas para sua prática. Nossa intenção, ao apresentar esse depoimento, é tão somente destacar que a surpresa do professor reside em colocar num tempo futuro a ideia de articular teoria e prática, mas que não necessariamente ele a realizará. Mas de toda forma ele traz para seu repertório pedagógico uma novidade, por assim dizer.

Ainda nesse mesmo artigo de Santos et al. (2012) encontramos o depoimento do Egresso B, em que foi possível identificar um aspecto da relação desse professor com as atividades realizadas no curso, que também se revelou no depoimento da professora Rúbia, quando ela afirma que "aplicou" nas suas aulas objetos de aprendizagem que conheceu no curso. Isto é, tanto num caso como no outro os professores levaram para suas salas de aula uma estratégia didática aprendida no contexto do MP. "O principal para mim (no mestrado) foi a motivação na utilização de recursos que eu não estava habituado a utilizar. Então isso me ajudou muito a trabalhar de maneira diferenciada com algumas turmas do colégio" (Egresso B reproduzido de SANTOS et al. 2012, p. 130, grifo nosso).

De forma semelhante, essa iniciativa em incorporar na prática pedagógica aprendizagens alcançadas no curso de MP e que sustentam um desenvolvimento profissional, também pode ser inferida em outros depoimentos extraídos do artigo de Pires e Iglori (2013).

Minhas aulas mudaram bastante este ano. Quando as preparo reflito sobre várias questões tratadas no curso. O caráter investigativo na abordagem dos assuntos tem sido prioridade. Acredito que estou motivando muito mais os alunos e tornando-os pessoas mais autônomas, na medida em que a exposição dos conceitos e procedimentos têm sido precedidas, quase sempre, por um processo de discussões com conjecturas e refutações dos alunos, na minha visão, muito enriquecedoras ao trabalho (Professor P3 reproduzido de PIRES; IGLORI, 2013, p. 1056, grifo nosso).

Muitas coisas que não faziam parte das minhas práticas pedagógicas mudaram, principalmente o uso de informática. No mestrado tive a oportunidade de cursar uma disciplina que seu enfoque era exatamente este, ainda preciso estudar mais o uso de tecnologia, mas ela já é uma realidade nas minhas aulas [...] (Professor P20 reproduzido de PIRES; IGLORI, 2013, p. 1057, grifo nosso).

Como se pode perceber, a relação dos professores com as atividades propostas pelo MP se revela por meio de diferentes formas. Nestes casos, o que se observa é o fato dos professores mostraremse satisfeitos não só por ter conhecido uma inovação com a qual se identificavam e se encantavam, mas sobretudo por tomarem a iniciativa de assumir a responsabilidade e o risco de desenvolver a inovação em sala de aula. Certamente entre o encantamento com uma proposta pedagógica e sua concretização em sala de aula há um passo que precisa ser dado, e nos parece que esses depoimentos ilustram esse movimento.

Outro elemento que nos chama atenção aparece quando o professor se dá conta de que é necessária uma dedicação considerável para se desenvolver profissionalmente a partir das atividades propostas pelo curso.

[...] quando ingressei no curso não tinha noção do monte de trabalho que tinha que fazer. Tanto que no começo fiquei preocupado com as duas primeiras disciplinas. [...] percebi que não dava para levar numa boa por conta do meu tempo. Eu tinha 54 aulas por semana. [...] tirava meu tempo de sono, os sábados e domingo para estudar (Professor Péricles reproduzido de CEVALLOS, 2011, p. 169, grifo nosso). 
Sem dúvida, essa dedicação irá variar, dependendo dos interesses pessoais e do envolvimento do professor com essas atividades, ou mesmo com as maneiras pelas quais elas se apresentam a ele. Depoimentos presentes no trabalho de Pires e Iglori (2013), também nos servem para caracterizar o reconhecimento dos professores acerca do esforço e do investimento requerido para dar conta de seu desenvolvimento profissional.

Participar das reuniões feitas durante os finais de semana com colegas do grupo de estudos, pesquisas em escolas, livros, internet, preparação dos assuntos a serem apresentados em seminários nas aulas. (Professor P21 reproduzido de PIRES; IGLORI, 2013, p. 1061, grifo nosso).

Mudou muito, pois me fez rever conceitos, mudar de comportamento, ler mais e buscar mais informações com o objetivo de melhorar a qualidade de minhas aulas de matemática. (Professor P16 reproduzido de PIRES; IGLORI, 2013, p. 1057, grifo nosso).

Como se pode notar, os dois depoimentos expressam diversas iniciativas que os professores precisaram empreender durante a realização do curso. No segundo depoimento, inclusive, o professor deixa claro o objetivo de seu esforço, qual seja, o de melhorar suas aulas. Não é exagero afirmar que, em geral, as pessoas mobilizam energia nas tarefas que realizam de modos diversos.

Finalmente, há ainda outro elemento que percebemos nos depoimentos de professores que participaram do curso de MP que se manifesta na qualidade das produções de natureza intelectual que podem ser realizadas no âmbito das atividades propostas e agregadas a sua trajetória profissional.

Já estou usando ferramentas tecnológicas disponíveis que temos como o Winplot, Graphmat, Cabrigeometre, Web Quest entre outras, muitas de graça que podemos criar e inovar no ambiente escolar. Isso é inacreditável, considerando que eu era bastante desinformatizada (Professor P12 reproduzido de PIRES; IGLORI, 2013, p. 1058, grifo nosso).

Em várias disciplinas fizemos análise de sequências didáticas que os livros didáticos trazem e que nós como educadores podemos interferir para buscar um maior rendimento para nossos alunos, reorganizando sequências apropriadas para nossos alunos (Professor P9 reproduzido de PIRES; IGLORI, 2013, p. 1061, grifo nosso).

Como se pode observar nos dois depoimentos, os professores relatam o fato de que puderam agregar novas metodologias ou estratégias didáticas à sua prática. Ao mesmo tempo, nos parece que pode haver diferentes maneiras pelas quais os professores introduzem essas inovações. Nos casos considerados, os professores tiveram o cuidado de recriá-las. No entanto, pode ocorrer do professor reproduzir uma estratégia, sem modificá-la, embora para sua prática ela represente uma inovação, como ilustra o depoimento da professora Rúbia.

[...] Eu não costumava usar recursos tecnológicos na sala de aula, então, eu conheci esses objetos, escolhi alguns que se encaixavam com o que eu estava trabalhando na escola e apliquei com os alunos na minha aula. [...] Aí quando eu fui apresentar na disciplina os objetos que eu tinha gostado eu pude também relatar a aplicação deles na sala de aula. (Rúbia reproduzido de MAIA, 2017, p. 99, grifo nosso).

Certamente os professores podem implementar uma inovação simplesmente reproduzindoa exatamente como a conheceu, sem passar por uma reflexão mais profunda e uma adaptação ao contexto de sua sala de aula. Isso nos sugere que as produções do professor também podem ser caracterizadas em função do quanto elas se constituem criativas e inovadoras em relação a suas necessidades e a seu conhecimento de base.

Em síntese, os depoimentos apresentados até aqui nos serviram para explicitar o fato de que, num contexto que se propõe a criar condições para o desenvolvimento profissional, o professor produz saberes e se relaciona com as atividades propostas de maneiras diferenciadas, expressando-se por meio de seu envolvimento com as atividades, de sua responsabilidade com aquisição e manutenção de novos conhecimentos e de sua iniciativa e criatividade ao incorporar inovações em sua prática. A nosso ver 
esses elementos podem caracterizar um conceito de autoria que estaria diretamente associado com o compromisso do professor em seu processo de desenvolvimento profissional.

Com esses elementos é possível iluminar o fato de que os professores podem experimentar um certo leque de possibilidades de autoria, ou seja, é possível caracterizar uma amplitude de aspectos que comporiam o que estamos chamando de autoria, no caso específico da relação que o professor estabelece com as atividades realizadas em um contexto de desenvolvimento profissional.

\section{UM ESQUEMA DE ANÁLISE PARA A AUTORIA DOCENTE}

$\mathrm{Na}$ perspectiva de sistematizar os elementos destacados na análise dos depoimentos, em outro patamar de elaboração, definimos três indicadores para caracterizar a autoria docente no ensino de Ciências.

Um primeiro indicador de autoria está associado à dedicação (investimento) do professor na realização das diferentes atividades propostas em um contexto formativo. A responsabilidade do professor em levar adiante tudo aquilo que pôde produzir durante o processo de formação, seja incorporando em sua prática, seja discutindo suas produções com seus pares em seu ambiente de trabalho, constitui-se num segundo indicador de autoria. Finalmente, um terceiro indicador está associado às inovações que o professor produz em relação àquilo que conhecia anteriormente, isto é, em relação a seu conhecimento de base. A inovação a que nos referimos, apesar de não excluir uma produção original ou totalmente inusitada do ponto de vista da produção de conhecimento na área de ensino de ciências, inclui de forma ampla práticas não usuais e que não faziam parte de seu repertório pedagógico.

Há que se considerar que, no âmbito da formação de professores, não há como rotular um nível de autoria para o professor independente da atividade na qual ele está envolvido, ou do contexto em que ele participa. Ou seja, a autoria, descrita pela composição dos indicadores definidos anteriormente, é um atributo da produção do professor que, para ser definida, implica em considerar diversos fatores relacionados à maneira pela qual ele se relaciona com determinada atividade formativa. Em termos práticos, a caracterização da autoria vai refletir o compromisso do professor de Ciências com seu desenvolvimento profissional.

Sentimos, assim, a necessidade de propor também, para cada indicador, níveis distintos que dariam ao conceito de autoria a flexibilidade necessária para melhor caracterizar particularidades nas maneiras pelas quais os professores se dedicam, se surpreendem com novos conhecimentos ou mesmo agregam inovações a seus repertórios pedagógicos e se responsabilizam pelo produzido.

Assim, admitimos que o indicador dedicação, caracterizado pelo esforço do professor para com a atividade desenvolvida durante o processo de formação, poderia assumir três níveis, quais sejam, nula, passiva e ativa.

A dedicação nula se caracteriza nas circunstâncias em que o professor deixa de investir na superação das dificuldades que encontra durante seu percurso formativo. Se tomarmos como exemplo o curso de MP, essas dificuldades podem ser numa disciplina, na relação orientador-orientando ou até mesmo na elaboração e desenvolvimento do produto educacional e da dissertação. Certamente os motivos podem variar, por exemplo, o professor pode desistir de uma disciplina ou do projeto por não se reconhecer capaz de aproveitar da atividade, por considerá-la complexa demais, por não ter uma formação suficiente para acompanhá-la, por não conseguir conciliar com interesses externos, ou, ainda, por não se implicar com as atividades propostas, isto é, não se assumir como participante e corresponsável pelo processo. Em todos esses casos a autoria seria considerada nula, na medida em que haveria um abandono ou rejeição ao que foi proposto pelo contexto formativo.

A dedicação passiva, por sua vez, se revela quando o professor se esforça apenas para atender estritamente o que lhe é exigido, sem se implicar efetivamente com a formação. Nessas circunstâncias o interesse do professor se limita, por exemplo, a obter exclusivamente ganhos na carreira profissional por meio do certificado: para tanto, investe somente o tempo e o esforço necessário. Outra situação em que é possível associar esse nível de autoria é aquela em que se estabelece uma relação de divergência entre o professor e a proposta formativa que, para ele, não dialoga com o contexto da prática 
escolar. Contudo, para não entrar em conflito com a proposta o professor, mesmo sem concordar, realiza aquilo que the foi solicitado.

Em contrapartida, quando o professor reconhece a possibilidade de contribuição do curso para a sua formação, parece não medir esforços e se envolve ativamente na busca do que lhe satisfaz. Nesse caso, o professor sente-se seduzido e estimulado por algum aspecto que lhe foi apresentado no contexto de formação, ou mesmo por uma demanda que já trazia, e fica satisfeito por vislumbrar novas possibilidades de atuação no seu contexto de trabalho. O atributo da autoria que se revela é dedicação ativa, em que o professor se dispõe a mobilizar a energia que considera necessária para conquistar seus objetivos. O grau de dedicação do professor com a atividade formativa certamente terá desdobramentos diversos sobre a forma com que ele se responsabiliza e agrega inovações ao seu repertório profissional.

O fato de o professor se declarar introduzido numa nova cultura didático-pedagógica, a ponto de incorporar alguma inovação em sua prática, é um indício que qualifica o indicador responsabilidade. Este, também pode ser definido, em princípio, a partir de três níveis: nula, eventual e sistemática. O que demarca a diferença entre esses níveis é o quanto o professor responde por aquilo que produziu, incorporando, ou não, suas produções e os saberes aprendidos em sua prática pedagógica rotineira.

Pode haver casos em que as produções realizadas durante o processo formativo não são valorizadas pelo professor a ponto de serem levadas adiante, ou seja, ele não se percebe responsável por divulgá-la em seu ambiente de trabalho ou mesmo por incorporá-la ao seu ideário pedagógico. Nesse caso, em que se pode considerar o indicador responsabilidade nula, as produções são realizadas tão somente para atender uma demanda do curso, por exemplo.

Uma responsabilidade eventual define uma qualidade para a autoria nas circunstâncias em que um professor explora ou experimenta colocar em prática um saber ou uma atividade em sala de aula, recentemente conhecida, tão somente durante o período em que participava do curso, ou mesmo de forma casual. Ao contrário, uma situação em que podemos classificar como responsabilidade sistemática é aquela em que o professor dá continuidade aos projetos desenvolvidos durante o curso ao longo de sua carreira. Nesse nível de autoria é provável que o professor tenha encontrado satisfação ao agregar em sua prática educativa diferentes aprendizagens; isso muitas vezes mobiliza o professor a dar prosseguimento nos projetos desenvolvidos no processo formativo.

A maneira como o professor se relaciona com suas produções e conhecimentos alcançados durante o processo formativo, concretizadas em projetos, saberes, elaboração de rotinas de gestão de sala de aula, roteiros de aula, sequências didáticas, entre outros, é relativamente diversificada. Para representar esse fato, foi criado um indicador denominado inovação, que também pode apresentar distintos níveis, quais sejam, inovação nula, técnica, reflexiva e criativa.

É muito comum professores em início de carreira que, por possuírem um conhecimento de base muito incipiente em termos dos saberes que compõem a profissão, se limitam apenas a aplicar, em geral sem uma reflexão profunda, métodos e estratégias didáticas que lhe foram prescritas pelas diretrizes e manuais didáticos. O professor que participa de cursos de MP, por exemplo, tem a possibilidade de entrar em contato com métodos, conteúdos, teorias de aprendizagem, estratégias de ensino entre muitos outros conhecimentos que para ele são inovadores em relação àquilo que já conhecia. Esses novos conhecimentos também podem ser interpretados pelo professor como um receituário, uma prescrição a ser implementada sem levar em consideração as particularidades do contexto da sala de aula, como por exemplo a diversidade cultural dos alunos, a estrutura escolar, entre outros. Esse tipo de relação que o professor estabelece com esses novos conhecimentos pode ser caracterizado por um nível de inovação técnica.

Por outro lado, quando o professor se depara com uma atividade que pouco ou nada lhe interessa, no sentido de que não considera que ela possa agregar conhecimentos ao seu repertório profissional ou ideário pedagógico, não somente sua dedicação será passiva, obedecendo unicamente às exigências institucionais, mas também a qualidade da inovação será nula. Casos em que isso pode ser caracterizado são aqueles em que professor não tem esperança de poder aproveitar algum conhecimento ensinado no MP em sua sala de aula, ou mesmo de explorá-lo como complementação de sua cultura. Nesse caso, a responsabilidade em dar continuidade ou revisar o que produziu também será nula.

Educação em Revista|Belo Horizonte|v.36|e236529|2020 
No entanto, há professores que aproveitam e exploram os conhecimentos produzidos durante o curso, estabelecendo com eles uma relação apoiada na possibilidade de solucionar problemas, tendo em vista determinados fins. Por meio da reflexão e da própria experiência, o professor procura entender, discutir e avaliar as diferentes propostas de ensino que podem fazer parte do seu repertório profissional. Nesse sentido, as inovações aprendidas são recriadas e adaptadas em acordo com práticas situadas. Assim, haveria um nível denominado inovação reflexiva no processo de constituição da autoria.

Finalmente, caberia ainda outro nível denominado inovação criativa no qual o professor se relaciona com os conhecimentos alcançados de forma muito semelhante ao que descrevemos no caso anterior, porém exibe um certo nível de insatisfação no sentido que percebe a possibilidade de ir além daquilo que aprendeu. Ou seja, reconhece que é possível ir além do aprendido e articular esses novos conhecimentos com outros na perspectiva de diversificar ainda mais rotinas em que se apoia para a condução das aulas e a sustentação das aprendizagens. Esse professor é aquele que, além de aproveitar os novos conhecimentos para criar práticas pedagógicas situadas, mantém um movimento constante que o impele a avançar no que diz respeito ao gerenciamento de sua carreira de magistério. Embora o professor reconheça o potencial do conhecimento novo, ele alimenta uma insatisfação no sentido de continuar buscando não só aprofundar o já aprendido, mas também reconhece que esse conhecimento é ainda limitado para dar conta das vicissitudes do ofício.

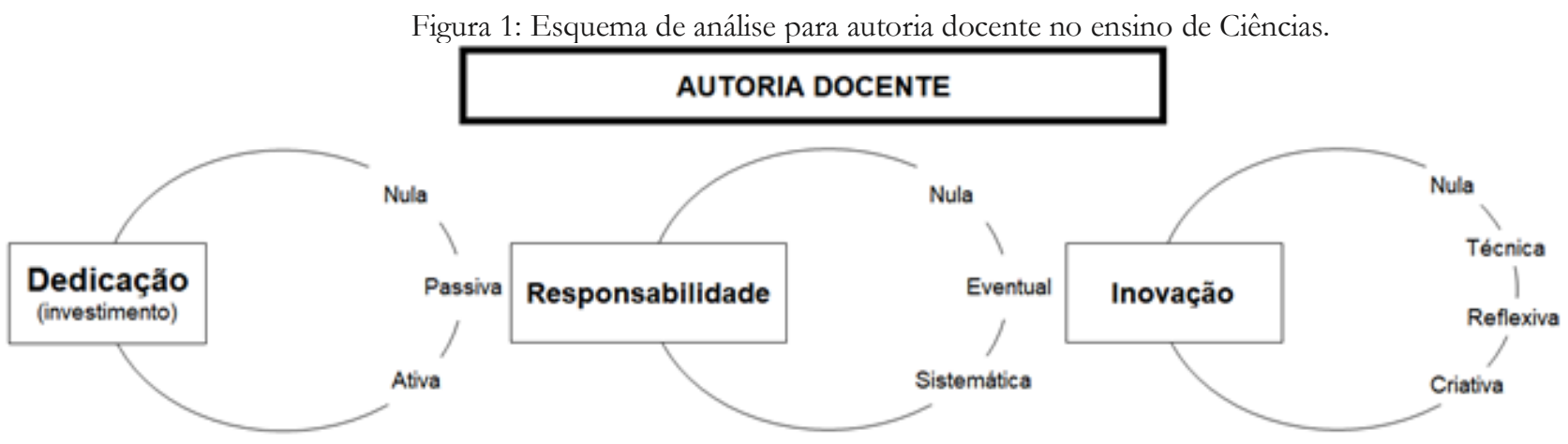

Fonte: Elaboração própria

\section{Explorando o esquema de análise: Uma autenticidade que leva a autoria - o caso de Francis no Mestrado Profissional}

A professora Francis concluiu o curso de Licenciatura em Física em 2006 numa universidade pública, embora tenha ingressado inicialmente na modalidade de Bacharelado do mesmo curso, no qual se graduou um ano depois. Após concluir o curso de Licenciatura, começou a lecionar em um Colégio de Aplicação, no mesmo ano em que teve conhecimento da existência do Mestrado Profissional em Ensino de Física (MPEF) na própria instituição em que lecionava.

Em 2006 eu terminei minha graduação e comecei a dar aula no Colégio de Aplicação e nessa escola a gente tinha interação com a universidade porque tinham projetos, parcerias, convênios, enfim... e numa dessas situações eu tive contato com um professor, que se tornou o coordenador da pós quando abriu, e foi meu professor na graduação também e aí ele me disse que ia abrir o programa e nós conversamos porque eu tinha interesse em fazer (PROFESSORA FRANCIS, 2015).

Ainda na graduação Francis tinha a pretensão de realizar o mestrado em Física. No entanto, um ano antes da conclusão do curso de Licenciatura, teve a oportunidade de participar do XVI Simpósio Nacional de Ensino de Física, ocasião em que assistiu a uma mesa redonda cujo tema era o mestrado profissional. A participação nessa discussão influenciou a decisão de Francis pela área de ensino. Em 2007 prestou seleção para o MPEF, iniciando o curso no ano seguinte. 
Como já tinha feito a graduação na mesma universidade, conhecia alguns professores que atuavam no MPEF, fato que contribuiu para escolha do orientador: o mesmo da graduação em que fez o Trabalho de Conclusão de Curso (TCC).

\begin{abstract}
Tanto o projeto quanto a escolha do orientador a gente faz depois que entra. [...] Eu tinha uma aproximação com meu orientador, porque eu tinha feito meu trabalho de conclusão de curso da licenciatura com ele. Uma vez que ele estava vinculado ao programa do mestrado entendi que seria natural seguir com ele. O meu TCC foi muito amplo, mas eu me ative na minha dissertação de mestrado à perspectiva que o meu orientador tinha sobre termodinâmica e eu trouxe alguns elementos referentes ao ensino para aglutinar, para que não fosse apenas vinculado à Física (PROFESSORA FRANCIS, 2015, grifo nosso).
\end{abstract}

De fato, a busca por um orientador já conhecido deveu-se também à vontade de Francis querer trabalhar com experimentos e com o conteúdo de física térmica, práticas que o orientador já desenvolvia. Provavelmente ela acreditou que fazendo essa parceria, o orientador poderia oferecer-lhe elementos valiosos para a sua atuação didática, em especial para desenvolver o produto educacional. "Eu só sabia que queria trabalhar com a experimentação porque eu gostava de Física térmica. [...] E daí eu decidi juntar a Física térmica que meu orientador também gostava de fazer, com esse aspecto do ensino e o projeto surgiu nesse contexto [...]" (PROFESSORA FRANCIS, 2015).

A professora apostava também que esse MPEF possibilitaria momentos de reflexão da sua própria prática, a discussão das teorias educacionais para apoiar o processo de condução de seu ensino e o desenvolvimento de sua dissertação.

Acho que eu buscava refletir sobre questões relativas ao ensino, tendo o conceito científico como algo super importante que não pode abrir mão dele, mas um pouco mais de reflexão do ensino, um pouco mais de pensamento relativos à educação. Sempre foi uma preocupação minha abordar questões de ensino. Com questões do ensino, eu quero dizer, procurar uma abordagem mais adequada, se vai ser história da ciência ou Física e arte. [...] Eu fui para o mestrado com a ideia de que se eu melhorar a minha prática eu vou ser uma professora melhor e tudo mais [...] (PROFESSORA FRANCIS, 2015, grifo nosso).

Entretanto, com o passar do tempo, Francis percebeu que seu orientador não daria conta de ajudá-la com questões relacionadas ao ensino de Física. Ao invés de se resignar e elaborar seu produto educacional com os elementos que seu orientador poderia lhe oferecer, a professora optou por manter sua perspectiva, no sentido de incorporar em sua prática, inovações em acordo com os resultados mais recentes da área de Ensino de Ciências. "[...] Então eu fui pensar: que situação, que contexto, que problema eu coloco para fomentar a necessidade e a pertinência desses experimentos. $\mathbf{O}$ meu orientador achava que isso não era importante. Então eu percebi que eu teria que buscar também outras pessoas" (PROFESSORA FRANCIS, 2015, grifo nosso).

Ou seja, ela reconheceu o limite de colaboração que seu orientador poderia the oferecer, bem como o investimento que ela deveria fazer para alcançar sua meta. Desse modo, é possível caracterizar esse movimento da professora como um forte indício de autoria, em particular no que se refere ao indicador dedicação. Mais que isso, uma dedicação que se revela no nível ativo, na medida em que ela se dá conta da necessidade em despender energia considerável para alcançar seus objetivos.

Francis percebeu também que o foco do MPEF que cursava concentrava-se em disciplinas com conteúdo específicos de Física e que estas não dialogavam muito com sua prática de sala de aula. De acordo com seu relato, a maioria dos professores que assumia as disciplinas de conteúdo específico não tinha tradição na área de ensino e parecia não ter experiência de atuação no ensino básico.

Então assim, basicamente se eu for fazer uma análise geral, o conteúdo específico era bastante presente, que inclusive é uma crítica minha não pela presença do conteúdo [...] tenho críticas a fazer a esse programa mesmo eu tendo feito ele [...] a crítica é essa ênfase nos conteúdos específicos. Repito de novo não é que não se deva trabalhar isso, mas é preciso também dar ênfase a outros elementos como educação, ensino, enfim questões de outras naturezas que são importantes para você fazer pesquisa e ensino de física também. [...] as relações do 
conhecimento específico com o ensino que você vai ter na escola ela não aconteciam tão frequentemente. Para mim isso é um defeito (PROFESSORA FRANCIS, 2015, grifo nosso).

[...] O corpo docente do programa na maioria são professores de física que dão aula no bacharelado, que fazem pesquisa em física e que publicam seus artigos em revistas de física e dão aula também no mestrado acadêmico em física pura. Então a gente não pode esperar que essas pessoas deem para gente o que nós estamos buscando talvez [...] mas, o programa deveria refletir sobre isso para saber que tipo de pessoa deveria estar lá também para poder nos oferecer isso e nos ajudar a aprofundar nos conceitos específicos fazendo relação com o ensino (PROFESSORA FRANCIS, 2015, grifo nosso).

Mesmo assim, a professora não deixou de tirar proveito do que a ela era oferecido. Entre as disciplinas de conteúdos de Física, uma contribuiu para a elaboração do produto educacional: a disciplina oferecida pelo seu orientador, que tinha como temática Termodinâmica. Embora pesquisador da área dura, na disciplina ele conseguia compatibilizar forma e conteúdo dentro dessa temática, relação que era perseguida pela professora.

A termodinâmica eu uso nas minhas aulas até pela minha inserção mais aprofundada e até pelo meu orientador que dava essa disciplina e as coisas que ele falava que eram mais próximas da minha sala de aula, não só o conteúdo específico, mas a maneira como ele colocava as análises dos gráficos, dos fenômenos, dos processos, e uma coisa que ele falava muito que eu também tenho como uma coisa importante é a questão das variáveis de estado que eu falo muito e com força no ensino médio. [...] Meu conhecimento em termodinâmica cresceu muito com o mestrado profissional. Isso é um fato. Eu aprendi muito mais e tenho certeza que minhas aulas são muito melhores por conta disso e me ajudou muito para fazer meu trabalho de mestrado. [...] Acho que eu consigo trazer para o aluno uma visão melhor do que eu traria se eu não tivesse feito a disciplina e não tivesse a orientação dele (PROFESSORA FRANCIS, 2015, grifo nosso).

Nesse depoimento, a professora afirma um certo encantamento com a maneira pela qual seu orientador abordava os conteúdos de termodinâmica, a ponto de inspirar sua prática e de lhe dar condição de alcançar um domínio maior naqueles conteúdos, tornando sua competência na transmissão e transposição didática, mais eficientes. A declaração da professora revela, mais uma vez, em termos de autoria, dedicação ativa, inclusive pela sua satisfação em vislumbrar novas possibilidades de atuação no seu contexto de trabalho. Além disso, é possível inferir que seu depoimento traz um indício de responsabilidade, no sentido de levar adiante em sua carreira, inovações que pôde experimentar durante o curso.

Entretanto, a disciplina que teve o potencial de influenciar mais intensamente seu desenvolvimento profissional e a elaboração do produto educacional, foi "Ensino por Investigação". Cabe destacar que tal disciplina passou a ser ofertada porque foi uma demanda da turma do mestrado de Francis. O tema de Ensino por Investigação foi discutido brevemente em outra disciplina chamada Tópicos em Ensino de Física, na qual a professora teve o primeiro contato com o tema, o que foi ao encontro das suas expectativas iniciais em relação ao MPEF.

[...] Nós pedimos à professora para ela ministrar uma disciplina só sobre isso, o ensino por investigação. [...] Então essa disciplina me marcou bastante pela maneira como ela foi colocada pela professora, as questões que a professora colocava. Você tinha que fazer no final dela uma proposta de atividade de investigação e apresentar para a professora avaliar, tinham textos que tínhamos que ler [...] Isso me impactou bastante porque me redirecionou para um caminho bem mais adequado, que eu entendo hoje, às minhas propostas que eu já tinha para elaborar o produto (PROFESSORA FRANCIS, 2015, grifo nosso).

Francis ficou muito encantada com a nova metodologia de ensino que havia aprendido, pois viu a possibilidade de desenvolver sua proposta de experimentos que comporia seu produto educacional. Em sua opinião, a elaboração de um trabalho de mestrado de boa qualidade requeria muito mais que um aglomerado de roteiros de experimentos. Além disso, não acreditava que apenas roteiros pudessem dar conta de contribuir para a aprendizagem dos alunos e que precisava encontrar uma abordagem ideal para 
utilizá-los. Em síntese, a professora já demonstrava um compromisso tanto com o trabalho final do curso, quanto com sua prática, que aqui se revela por meio da preocupação com a aprendizagem dos alunos.

\begin{abstract}
Na questão do produto eu sabia que podia ser experimentos e eu fiquei pensando em como fazer isso, me questionando em estar no mestrado e só fazer experimentos. Então na verdade, o que me ajudou com meu trabalho do mestrado foi que nessa disciplina que eu fiz sobre o ensino por investigação a gente tinha que levar uma proposta, claro que eu levei uma das minhas, para ver o que ela [professora] avaliava e o que ela [professora] achava. Era a proposta de um dos meus experimentos, e ela [professora] sempre questionava algo que ecoa até hoje, que era: "que pergunta você vai fazer para o aluno e que contexto de experimento que você tem que fazer? Que problema você vai colocar para o aluno? Como você vai problematizar seu experimento?" Ela sempre problematizava coisas que a gente achava que era trivial. Eu tinha isso muito em consideração. Então o que eu fiz? Na verdade, foi elaborar situações que dessem sentido aos experimentos, para não levar os experimentos só por experimento. Então eu fui pensar que situação, que contexto, que problema eu coloco para fomentar a necessidade e a pertinência desses experimentos? [...] A professora colocava questionamentos sobre a forma de conduzir a experimentação, sobre a utilidade do roteiro, por exemplo (PROFESSORA FRANCIS, 2015, grifo nosso)
\end{abstract}

O processo de produção de uma proposta orientada pelo ensino por investigação trouxe para a professora um questionamento sobre um material que ela já havia desenvolvido, qual seja, um conjunto de roteiros de experimentos. Esse questionamento fundamentou-se nas problematizações que a docente da disciplina realizava sobre o material trazido pelos professores. E isso contribuiu decisivamente para que Francis refletisse sobre o já produzido e buscasse recriá-lo de modo a contextualizar, com bases em situações cotidianas, esses experimentos, tendo em vista a aprendizagem. Nesse sentido, nos parece bastante plausível afirmar que, do ponto de vista do nosso esquema de autoria, o processo vivenciado por Francis enquadra-se num patamar de inovação reflexiva.

Além disso, nos chama a atenção o fato de que a professora não apenas se encantou com a metodologia apresentada na disciplina de Ensino por Investigação, mas também a levou para sua prática, incorporando-a a seu repertório pedagógico. Esse fato é, em nossa interpretação, um forte indício de que sua autoria se caracteriza também por um nível de responsabilidade sistemática.

É uma proposta muito adequada da qual eu sempre vejo resultado com meus alunos quando eu faço essas atividades com eles e eu percebo que gera um impacto positivo. [...] Eu agradeço a ela [professora do MP] essa abertura dos olhos que ela me fez ter. Eu percebi que o roteiro para a experimentação não faz você pensar! Então eu me encantei com essa ideia de fazer o aluno pensar, de fazê-lo refletir e de colocar questões (PROFESSORA FRANCIS, 2015, grifo nosso).

Porém, mesmo reconhecendo a importância desses novos conhecimentos para sua formação, em outros depoimentos, a professora foi enfática ao afirmar certa insatisfação com tudo o que pôde aprender e explorar no curso.

Eu gosto de ensino, eu gosto de educação e por isso, eu li outras coisas para não ficar só nas leituras sugeridas, como consequência disso eu acabei querendo buscar outras coisas. [...] A princípio eu pensava em parar depois do mestrado, eu queria me dedicar ao trabalho, mas por conta dessas faltas na minha formação durante o mestrado eu comecei a fazer umas disciplinas em outro instituto de outra universidade. Eles ministravam umas disciplinas condensadas de uma semana durante os períodos de férias, então eu fiz várias disciplinas. [...] Eu tinha o desejo de saber aquelas coisas que eu achava que eram importantes, como a teoria de aprendizagem, que eu não tinha no meu programa, mas eu gostava, porque eu tinha aula na graduação, mas depois do mestrado isso aparecia, mas aparecia mais fluido (PROFESSORA FRANCIS, 2015, grifo nosso).

Com esse depoimento, nos parece evidente o fato de que Francis tem um movimento de busca de conhecimentos bem marcado em relação às suas próprias demandas de formação. Em outras palavras, deixa clara sua autonomia em relação aos conhecimentos que considerava como sendo 
fundamentais para sua constituição docente. Nesse sentido não só fez leituras para além daquelas exigidas no curso, mas também procurou, em concomitância ao MPEF, outro curso que pudesse reparar as falhas de formação que identificava. Por todo esse seu envolvimento com a profissão docente, é possível afirmar que em termos do indicador inovação, além de atingir o patamar de inovação reflexiva, ele se configurou também no nível de inovação criativa, inferência que pode ser, inclusive, reafirmada pela avaliação que a professora realiza sobre seu próprio desempenho.

Os produtos que eu produzi são meus, são mais meus que do meu orientador, não que eles sejam perfeitos, mas são coisas que eu consegui produzir e de certo sentido é uma coisa que me dá uma certa autonomia, eu consegui ser capaz mediante aquilo que me foi informado e passado e isso foi importante para eu ter elaborado isso e ter esse produto (PROFESSORA FRANCIS, 2015, grifo nosso).

Em síntese, o caso da professora Francis nos parece bastante emblemático. Como pudemos ilustrar, os indicadores de dedicação, responsabilidade e inovação foram todos qualificados em relação aos níveis, ativo, sistemático e criativo, respectivamente. Nesse sentido, é possível afirmar que a professora apresenta um elevado compromisso com seu desenvolvimento profissional, pois seus depoimentos revelam uma autoria bastante singular na relação que estabeleceu com algumas das disciplinas cursadas, com seu orientador e com a elaboração de seu produto educacional.

\section{CONSIDERAÇÕES FINAIS}

Como se pode notar, o conceito de autoria docente aqui desenvolvido, possui uma sofisticação considerável frente à maneira como tem comparecido na literatura educacional (DIAS; ALMEIDA, 2010; NASCIMENTO; REZENDE JÚNIOR, 2010; ALMEIDA, 2012; MASSI; QUEIROZ, 2012; GOIS; SANTOS, 2014), em particular no que se refere aos trabalhos apoiados em Eni Orlandi (2004), circunscritos ao âmbito das formações discursivas, em acordo com as categorias de repetição empírica, formal e histórica. Buscamos, aqui, caracterizar esse conceito de modo a aprofundar a relação que o professor, em contextos de formação continuada, estabelece com seu próprio desenvolvimento e com o planejamento de sua carreira. Assim, a autoria está associada a um compromisso do professor com a profissão, numa vertente de cunho subjetivo, pois incorpora não apenas a horizontalidade própria, de dimensões do desenvolvimento profissional, mas também a verticalidade da relação do sujeito com cada uma dessas dimensões.

O caso da professora Francis, por exemplo, nos permitiu inferir não só a abrangência de seu processo de desenvolvimento profissional, que foi proporcionado pela sua participação no curso de MP, mas, sobretudo, a autoria, isto é, a qualidade com que realizou as atividades oferecidas por esse curso. Assim, por meio das disciplinas cursadas, da elaboração do produto educacional e da relação com o orientador, ela pôde avançar em várias dimensões do desenvolvimento profissional em termos de uma atualização, tanto no conhecimento científico, quanto no pedagógico, bem como nas formas de conduzir o ensino e sustentar a aprendizagem dos alunos. Além disso, nesse processo, realizou continuamente uma reflexão sobre a própria prática, o que lhe permitiu, ainda, encontrar novos elementos para planejar com mais cuidado, sua carreira. Ou seja, em sua participação no curso de MPEF, nossos dados indicam que a professora pôde se desenvolver em praticamente todas as dimensões do desenvolvimento profissional (BAROLLI et al., 2019). Assim, a análise que realizamos refletiu um desenvolvimento profissional bastante almejado por um processo de formação continuada.

Entretanto, todos esses aspectos relacionados ao processo de desenvolvimento profissional poderiam ter ocorrido em diferentes níveis de intensidade, pois cada um desses aspectos admite diferentes gradações, que podem ser caracterizadas pelo esquema de autoria aqui proposto. E são justamente os indicadores desse conceito que podem avaliar a profundidade com que um professor se desenvolveu num determinado aspecto. Nesse sentido, o conceito de autoria, como desenvolvido neste trabalho, busca dar sentido ao fato de que o desenvolvimento profissional não é um processo linear; ou seja, até este momento, a literatura vem acenando com a importância de o professor vivenciar esse 
processo em contextos de formação continuada, porém essa mesma literatura não dá conta de suas idiossincrasias.

Há que se considerar, ainda, que o esquema desenvolvido para caracterizar a autoria docente pode se constituir num instrumento efetivo, seja para o professor se autoavaliar, seja para fornecer indícios acerca do potencial de contribuição das atividades propostas pelo contexto formativo.

Certamente o conceito de autonomia em Contreras (2002) tem pontos de convergência com o conceito de autoria aqui desenvolvido, sobretudo porque os dois conceitos se fundamentam na prática educativa. O especialista técnico, como considera Contreras (2002), tem uma autonomia ilusória, o que em termos de autoria poderia representar, por exemplo, um professor cuja autoria seria descrita por uma dedicação passiva, uma responsabilidade eventual ou até mesmo sistemática, e uma inovação técnica. $\mathrm{O}$ profissional reflexivo, por sua vez, caracterizado por uma autonomia moral e individual, poderia ter uma autoria descrita por uma dedicação ativa, uma responsabilidade sistemática e uma inovação reflexiva ou criativa. A concepção de autoria que desenvolvemos, não abrange a característica que, a nosso ver, é aquela que marca a diferença entre o profissional reflexivo e o intelectual crítico, qual seja, o comprometimento com uma transformação social e política.

No caso da professora Francis, cuja autoria pôde ser caracterizada pelos patamares de dedicação ativa, responsabilidade sistemática e inovação criativa, não temos elementos para saber se, do ponto de vista da autonomia docente, ela poderia ser considerada uma intelectual crítica. Isso porque a autonomia, como conceituada por Contreras (2002), pressupõe que a profissão docente tem um viés político-social e os nossos dados não contemplaram elementos que nos dessem indícios sobre a maneira pela qual se efetiva sua relação com os valores ideológicos dominantes. De toda forma, esse viés também comparece nas dimensões previstas para o desenvolvimento profissional docente (BAROLLI et al., 2019) e que certamente pode ser descrito pelos indicadores de autoria: dedicação, responsabilidade e inovação.

Em síntese, as elaborações de Contreras (2002), a nosso ver, procuram diferenciar a atuação profissional docente numa perspectiva macro; em contrapartida, nosso esquema tem como perspectiva dar destaque ao fato de que o professor pode ser original e criativo também quando se considera, em específico, os conhecimentos que podem estar relacionados com as diversas atividades da prática pedagógica.

\section{REFERÊNCIAS}

ALMEIDA, Maria José Pereira Monteiro de. O imaginário de estudantes de licenciatura sobre exercícios em aulas de física. Nuances: estudos sobre Educação, Presidente Prudente, v. 22, n. 23, p. 57-71, 2012.

BAROLLI, Elisabeth.; NASCIMENTO, Wilson Elmer.; MAIA, Juliana de Oliveira.; VILLANI, Alberto. Desarrollo profesional de profesores de ciencias: dimensiones de análisis. Revista Electrónica de Enseñanza de las Ciencias, v. 18, n. 1, p. 173-197, 2019.

CEVALLOS, Ivete. O mestrado profissional em ensino de matemática e o desenvolvimento profissional de professores: um desafio institucional. Tese, Doutorado em Educação Matemática, Pontifícia Universidade Católica de São Paulo, São Paulo, 2011.

CLANDININ, D. Jean.; CONNELLY, F. Michael. Pesquisa narrativa: experiência e história em pesquisa qualitativa. Tradução do Grupo de Pesquisa Narrativa e Educação de Professores ILEEI/UFU. Uberlândia, MG: EDUFU, 2011.

CONTRERAS, José. A autonomia de professores. São Paulo: Cortez, 2002.

CURI, Edda; AMARAL, Luiz Henrique. Dez anos de Mestrado Profissional em Ensino de Ciências e Matemática: a contribuição da pesquisa para a educação básica. Polyphonía, v. 24, n. 2, p. 285-302, 2013. 
CURY, Fernando Guedes. De Narrativas a Análises Narrativas: reflexões sobre a análise de depoimentos em pesquisas de história da educação (matemática). Alexandria Revista de Educação em Ciência e Tecnologia, v. 6, n. 1, p. 143-164, 2013.

DAY, Christopher. Desenvolvimento profissional de professores: os desafios da aprendizagem permanente. Porto: Porto Editora, 2001.

DIAS, Ricardo Henrique Almeida; ALMEIDA, Maria José Pereira Monteiro. A repetição em interpretações de licenciandos em Física ao lerem as revistas Ciência Hoje e Pesquisa FAPESP. Ensaio: Pesquisa em Educação em Ciências, Minas Gerais, v. 12, n. 3, p. 51-64, 2010.

DUARTE, Rosália. Entrevistas em pesquisas qualitativas. Educar, Curitiba, n. 24, p. 213-225, 2004.

GOIS, Mara Elisângela Jappe; SANTOS, Flávia Maria Teixeira dos. Formação de professores e o desenvolvimento de habilidades para a utilização da metodologia de resolução de problemas. Investigações em Ensino de Ciências, v. 19, n. 2, p. 431-450, 2014.

GUIMARÃES, Maria de Fátima. Modelos de conhecimento do professor e prática lectiva. In: SEMINÁRIO SPCE. Anais do Seminário Tróia - Aprendizagens em Matemática. Faculdade de Ciências da Universidade de Lisboa, 1996. Disponível em: http://spiem.pt/DOCS/ATAS_ENCONTROS/1995/1995_04_MFGuimaraes.pdf. Consultado em 20 de março de 2018.

MAIA, Juliana de Oliveira. Investigando o desenvolvimento profissional docente em Mestrados Profissionais em Ensino de Ciências. Tese. (Doutorado em Ensino de Ciências). Universidade de São Paulo, São Paulo, 2017.

MARCELO, Carlos. Desenvolvimento profissional docente: passado e futuro. Sísifo: Revista de Ciências da Educação, n. 8, p. 7-22, 2009.

MASSI, Luciana; QUEIROZ, Salete Linhares. Investigando processos de autoria na produção do relatório de iniciação. Ciência e Educação, Bauru, v. 18, n. 2, p. 271-290, 2012.

NASCIMENTO, Tatiana Galieta; REZENDE JÚNIOR, Mikael Frank. A produção de textos de divulgação científica na formação inicial de licenciandos em ciências naturais. Revista Brasileira de Pesquisa em Educação em Ciências, v. 10, n. 1, p. 97-120, 2010.

NÓVOA, Antônio. Professores: Imagens do futuro presente. Lisboa: EDUCA, 2009.

ORLANDI, Eni. Interpretação: autoria, leitura e efeitos do trabalho simbólico. Petrópolis: Vozes, 2004.

PEREIRA, Júlio Emílio Diniz. Pesquisa de histórias de vida e os contextos sócio-culturais na formação docente. In: $13^{\circ}$ Encontro Nacional de Didática e Prática de Ensino (ENDIPE), Recife, PE, 2006. Anais... Recife, PE, CD-ROM, 2006.

PERRENOUD, Philippe. Dez novas competências para ensinar. Porto Alegre: Artes Médicas Sul, 2000.

PIRES, Célia Maria Carolino; IGLORI, Sonia Barbosa Camargo. Mestrado Profissional e o desenvolvimento profissional do professor de matemática. Ciência e Educação, Bauru, v. 19, n. 4, p. 1045-1068, 2013. 
PONTE, João Pedro da. Da formação ao desenvolvimento profissional. In: Actas do ProfMat. Lisboa: APM, p. 27-44, 1998.

PROFESSORA FRANCIS. Entrevista. Rio de Janeiro (Rio de Janeiro), 2015. Disponível no acervo pessoal dos autores.

SANTOS, Sonia Regina Mendes et al. Didáticas específicas, novas tecnologias e formação de professores para o ensino das Ciências na baixada fluminense: a experiência do mestrado profissional da Universidade do Grande Rio. Revista Brasileira de Pós-Graduação, Brasília, v. 9, n. 16, p. 115 - 138, 2012.

SCHÄFER, Eliane Dias Alvarez; OSTERMANN, Fernanda. Autonomia profissional na formação de professores: Uma análise de entrevistas realizadas num mestrado profissional em ensino de física. Revista Electrónica de Enseñanza de lãs Ciências, v. 12, n. 2, p. 287-312, 2013 a.

SCHÄFER, Eliane Dias Alvarez; OSTERMANN, Fernanda. O impacto de um mestrado profissional em ensino de Física na prática docente de seus alunos: uma análise bakhtiniana sobre os saberes profissionais. Ensaio: Pesquisa em Educação em Ciências, n. 15, v. 2, p. 87-103, 2013b.

TRIVIÑOS, Augusto Nibaldo Silva. Introdução à Pesquisa em Ciências Sociais: a pesquisa qualitativa em educação. São Paulo, SP: Atlas, 1992.

VILLEGAS-REIMERS, Eleonora. Teacher professional development: an international review of the literature. International Institute for Educational Planning, 2003.

Submetido: $14 / 04 / 2020$

Aprovado: 14/09/2020 